built the yacht Anthracite, which crossed the Atlantic using steam at 350 lb. per sq. in. ; Joseph Vavasseur (1834-1908) is remembered for his improved method of controlling the recoil of large guns, while Walter Bentley Woodbury (1834-85) was the inventor of Woodburytype and other developments in photography. Sir William Preece (1834-1913) was widely known as a distinguished electrical engineer; Gustav Hermann Wedding (1834-1908) was both an honorary member and Bessemer medallist of the Iron and Steel Institute ; while Gottlieb Daimler (1834-1900) will always be remembered as the colleague of Langen, Otto and Maybach, and as the first to construct a high- speed internal combustion engine suitable for road vehicles.

In conclusion, passing reference may be made to the approaching centenaries of the birth of Sir John Lubbock, first Lord Avebury (1834-1913) which falls on April 30, 1834, whose writings on primitive man and on bees and ants delighted a large circle of readers; of August Weismann (1834-1914) the German biologist, born on January 17, 1834, who was the first to think out a coherent theory of heredity, and of Ernst Heinrich Haeckel (1834-1919), born on February 16, 1834, who has been spoken of as "probably the most influential advocate of Darwinism".

\title{
Experiments in the Stratosphere
}

T has recently been reported in the daity Press that an attempt is shortly to be made by balloon ascent to reach higher altitudes than $61,000 \mathrm{ft}$. (pressure $50 \mathrm{~mm}$.) claimed to have been reached by Prokofiev and his companions in the U.S.S.R. balloon. It is to be recalled that observations were made by Regener in 1932 using self-registering apparatus attached to rubber balloons up to a pressure of $22 \mathrm{~mm}$. It was reported that the American balloonists Settle and Fordney reached a pressure last autumn of about $64 \mathrm{~mm}$., whilst the minimum pressure from the records of the Belgian flights of Cosyns, Kipfer and Piccard was $73 \mathrm{~mm}$.

The new attempt represents a departure from the previous methods in that the observers are to travel in an open basket but will themselves be completely sealed in flexible rubber suits. To prevent these from ballooning at low external pressure the suits, adequately supported, will be exhausted down to the minimum that a man can withstand with comfort if he be supplied with sufficient oxygen. The advantages claimed are that the great saving in weight by the absence of the heavy gondola of the previous flights will enable the observers to reach greater heights. The apparatus has already been tested with safety up to an external pressure supposed to correspond to a height of $90,000 \mathrm{ft}$.-roughly that attained by Regener's balloons. These preparatory ground experiments are being conducted by an American, Mr. M. E. Ridge, with the advice of Dr. J. S. Haldane, at the works of Messrs. Siebe, Gorman and Co. Ltd. at Lambeth, London. It is assumed that the ballooning of the suit at the greatest height attainable will not incommode the occupant even though he himself is under a very much reduced pressure. The observer will be enabled to move about freely and make meteorological and other observations with instruments in contact with the atmosphere.

It is true that from the point of view of record breaking, this saving in weight is an important feature, for it was made clear by Dr. M. Cosyns, when lecturing in England a short time ago, that the only practical limits imposed turned on the very awkward elongated cigar shape of an extremely large envelope when filled with hydrogen only to a small fraction-one fifth or one tenthof its capacity on the ground. The whole risk lies with the possible entangling of the practically parallel ropes supporting the gondola. When once off the ground the mishap cannot be rectified. So great was the risk that, in the last Belgian ascent, the balloon was purposely filled with twice as much hydrogen as was required in order to keep the ropes apart, the surplus being discharged en route.

Turning now to the instrumental observations, it must be remarked at the outset that the values of $J$, the rate of production of ions per cubic centimetre by the cosmic rays, obtained by the Belgian observers, lie within the limits of those of Regener and agree well with them. Those of the stratostat $U S S R$ are said to agree slightly better with the Belgian than with Regener's results. Other interesting experimental results from the Russian source are that the composition of the air is the same at the lowest pressure reached as on the ground, the relative humidity fell from 92 per cent on the ground to 42 per cent on the borders of the stratosphere and that, contrary to expectations, gradients of temperature over a few degrees were experienced within the stratosphere. It is noticeable, however, that previous observers have attempted rather too much on each flight, but commenting on the new departure and its relation to previous methods, the barothermograph looks after itself, as does the recording electrometer for obtaining the potential gradient. Perhaps a small advantage would be obtained here in manipulating the leads strung out from the car. The Kolhörster ionisation chamber failed to work on the Belgian flight due to the deposition of body moisture on the insulations, but the advantages of exposing the battery, insulators, electrometers, etc., to the rigorous conditions of the stratosphere are doubtful. Spectrometers for recording the sun and sky light, pyrheliometer for determining the solar constant, air samplers and camera can all be worked in the open. Eyes and ears must unfortunately always 
be enclosed. The deep purple of the sky noticed by both the Belgian and the Russian observers must always be seen through glass.

Of all the observations likely to be made, the greatest promise comes from the projected Wilson chamber experiments by Dr. Cosyns that were mentioned in NATURE of November 25, p. 812. The need for a further examination of cosmic rays is urgent, for their origin remains unknown. The interesting effect accentuated in the Belgian flights was the difference in the behaviour of the ionisation chamber and the Geiger counter as standardised on the ground with $\gamma$-rays from radium and used in the upper atmosphere. The relative indications of the counter increase at a greater rate than those of the ionisation chamber, and in the highest altitudes reached, the activity of one has become thrice that of the other. The greater attenuation of the ions along the track of the cosmic ray than along that of the standardising $\beta$-ray accounts for the comparative falling off of the indications of the ionisation chamber, whilst the counter goes on no matter how small the disturbance. This result, however, is deceptive, for as the ground experiments of Blackett and Occhialini have abundantly shown, only a very inadequate part of the life-history of a cosmic ray may be obtained from the study of a localised portion of the track of one of the secondary particles. The intrinsic ionisation per centimetre along the track with its secondaries and tertiaries may be just as high as along that of a $\beta$-ray. It is well known that, of all the instruments, the Wilson chamber set for photographing $\beta$-rays and cosmic rays is most delicately poised. Small variations in temperature conditions and expansion ratio with water or alcohol vapour as indicator upset the observations. Such an instrument, if it is ever constructed for the purpose, must be used in a closed gondola, on account of its heavy coils for obtaining the requisite magnetic field and extra large chamber for taking in as much as possible of these simultaneous happenings, the non-ionising links, the tracks radiating forwards from diffuse centres consisting of neutral particles and positive and negative electrons and the localised heavy bursts of ionisation supposed to be associated with the complete destruction of a chance heavy molecule.

Apart from the investigations in pure science for which such heroic efforts have recently been made and are likely to be made in the future, the reported change in tactics has reopened the question of the feasibility of employing such a flying suit in an open aeroplane flying the stratosphere. It is claimed that the control will be easier than from a completely sealed cockpit.

\section{Obituary}

Mr. H. R. A. Mallock, F.R.s.

$\mathrm{W}$ HEN Mr. Henry Reginald Arnulph Mallock died on June 26, 1933, we endeavoured to find particulars of his career upon which a suitable obituary notice could be based, but were unsuccessful. He was an esteemed contributor to our correspondence columns, yet, on account of his dislike for publicity, few personal details were known concerning him, and no one felt able, therefore, to deal adequately with his life and work. Dr. C. V. Boys has, however, since contributed to the Proceedings of the Royal Society an appreciative account of Mallock's upbringing and some of the products of his fertile brain and mechanical ingenuity. We give below an abridgement of this obituary notice and are glad thus to be able to place on record a tribute to a great physicist and engineer.

Arnulph Mallock, the youngest son of the Rev. William Mallock, was born at Cheriton Bishop, on March 12, 1851. After leaving school he entered St. Edmund's Hall, Oxford, and when he left Oxford he assisted his uncle, Mr. W. Froude, of Chelston Cross, Torquay, in working out the very beautiful gear of the original ship model tank. In 1876 Mallock went as assistant to the late Lord Rayleigh. He had some doubt whether his mechanical skillwould be sufficient to enable him to meet Lord Rayleigh's requirements. It would seem that his misgivings were unnecessary for two reasons. He was in fact an accomplished mechanic, capable of the finest instrument construction if he had suitable tools, and Lord Rayleigh was such a genius in devising means almost absurdly simple for conducting experinents of the most crucial character. The time spent under that benign influence must perhaps have been the most precious of all in encouraging Mallock, if indeed he needed encouragement, in confidence in first principles where difficult problems were to be met.

Mallock was fortunate in having lived among a group of brilliant men in the engineering world -Brunel, Froude, Tower, of spherical engine fame, Baker, Metford and others-and with his very great mechanical skill and considerable mathematical ability and ingenuity, was ready to attack and solve problems as they arose.

Perhaps the class of experiment for which Mallock showed especial genius was any in which the smallest movements, tremors, bendings or stretchings had to be determined. He designed and either made himself or designed and superintended the construction, by the firms of Troughton and Sims or Adie in particular, of the beautiful instruments with which he examined tremors due to the underground railway, disturbances of St. Paul's Cathedral, problems connected with the Forth and Tower Bridges and many more. As a civilian member of the Ordnance Committee he wrestled with many of the problems of ballistics.

Mallock was also interested in many problems in optics, and in particular he was skilled in dissection under the microscope and wrote many 